NURSING CONSULTATION CONCERNING SEXUALITY: AN INSTRUMENT FOR WOMEN'S NURSING HEALTHCARE AT THE LEVEL OF PRIMARY HEALTHCARE

\author{
Olga Regina Zigelli Garcia ${ }^{1}$, Laura Cristina da Silva Lisboa²
}

\author{
${ }^{1}$ Ph.D. in Human Sciences. Associate Professor, Federal University of Santa Catarina, Nursing Department (UFSC). Santa \\ Catarina, Brazil. E-mail: zigarcia@gmail.com \\ ${ }^{2}$ Ph.D. in Nursing. Associate Professor, UFSC, Nursing Department. Santa Catarina, Brazil. E-mail: enflislaura@gmail.com
}

\begin{abstract}
Understanding sexuality as a component of health and based on their professional experience as nurses and professors in the context of nursing at the primary healthcare level, the authors present a nursing consultation concerning sexuality. Throughout the paper, they seek to show the importance of apropriating knowledge in this field for the professional practice of nurses at the primary healthcare level. They conclude that deepening the study of human sexuality, especially female sexuality, is one of the demands in the education and practice of nurses. Deepened understanding in this field enables nurses to provide primary heatlhcare congruent with the population's health needs, especially women's health needs, in line with what is recommended by the National Nursing Curricular Guidelines.
\end{abstract}

DESCRIPTORS: Sexuality. Nurse. Women's health. Primary health care.

\title{
CONSULTA DE ENFERMAGEM EM SEXUALIDADE: UM INSTRUMENTO PARA ASSISTÊNCIA DE ENFERMAGEM À SAÚDE DA MULHER, EM NÍVEL DE ATENÇÃO PRIMÁRIA
}

RESUMO: Trata-se de um artigo no qual as autoras, entendendo a sexualidade como um componente da saúde e fundamentadas no relato de sua experiência profissional como enfermeiras, a partir da docência em enfermagem no contexto da atenção primária em saúde, apresentam a consulta de enfermagem em sexualidade. Ao longo do texto buscam demonstrar a importância da apropriação do conhecimento desta temática para a atuação profissional do enfermeiro em nível de atenção primária à saúde. Concluem que aprofundar-se no estudo da sexualidade humana, em especial a feminina, é uma das demandas na formação e atuação de profissionais enfermeiros. Este aprofundamento possibilita um cuidado em atenção primária comprometida com as necessidades de saúde da população, em especial, as necessidades de saúde da mulher, em consonância com o que é preconizado pelas Diretrizes Curriculares Nacionais para enfermagem.

DESCRITORES: Sexualidade. Enfermeiro. Saúde da mulher. Atenção primária à saúde.

\section{CONSULTA DE ENFERMERÍA EN SEXUALIDAD: UN INSTRUMENTO PARA EL CUIDADO DE ENFERMERÍA PARA LA SALUD DE LA MUJER EN ATENCIÓN PRIMARIA}

RESUMEN: Este es un artículo en el que los autores, comprenden la sexualidad como un componente de la salud, basado en la experiencia y la enseñanza de enfermería en el contexto de la atención primaria de la salud, presentes en las consultas de enfermería la en sexualidad. En todo el texto se busca demostrar la importancia de la propiedad del conocimiento de este tema para la práctica profesional de las enfermeras en la atención primaria a la salud. Se llega a la conclusión de que profundizar en el estudio de la sexualidad humana, en especial con mujeres, es una de las demandas en materia de formación y desempeño de las enfermeras profesionales. Esto permite además un cuidado en la atención primaria comprometidos con las necesidades de salud de la población, en particular las necesidades de salud de las mujeres, en línea con lo recomendado por las Directrices Curriculares Nacionales para la Enfermería. DESCRIPTORES: Sexualidad. Enfermera. Salud de la mujer. Atención primaria de salud. 


\section{INTRODUCTION}

As a consequence of the so-called "sexual revolution", we currently live in a time of liberation in which many standards, myths, and taboos related to sexuality have been overcome and/or deconstructed. We are continuously stimulated to expand our sexual desires and seek individual freedom. Various types of knowledge concerning sexuality are increasingly more socialized. It is possible to state that sexuality is a topic broadly in evidence in the culture and all this context forms, in modern times, a "sexuality device"1:244 in a dynamic relationship, in constant movement, between deconstruction and construction of knowledge, standards and values.

Despite the importance human sexuality has currently acquired, there is a scarcity of studies addressing this topic and its relationship with grounding care practices of nursing directed to increasingly more frequent complaints related to sexuality at the primary healthcare level. Hence, discussing the topic in scientific papers will allow deficiencies identified in undergraduate nursing programs concerning this subject and the quality of related healthcare delivery to be better understood. ${ }^{2}$

A brief retrospective reveals that the graduation of unprepared nurses, ${ }^{3}$ mainly in the field of promoting healthy behavior, already drew attention in the 1970s. Only reproduction and the maternity cycle were taught to students at the time, without addressing sexual knowledge in the cognitive and affective dimensions. Omitting the study of human sexual behavior in the nursing curricula hinders nurses' education since situations of this nature are observed in practice. "Excluding this discipline is a failure of nursing professors in providing knowledge that would enable meeting the real needs of clients and the public" $3: 78$

A study conducted by the World Health Organization (WHO) in 1973 reports that nursing curricula at the time focused on translating the holistic essence of healthcare into the theoretical discourse of educators, however, professional practice continues to deny the existence of such an essence. The message, according to the study, was that the human being is important in all his/her aspects except the sexual aspect. The tendency, therefore, seemed to be the denial of such an aspect. ${ }^{4}$
In the 1980s, people realized that the resistance usually observed among some nursing professors in including content related to sexuality in the program's curricula was due to a lack of sexual knowledge and information in their own background. Whenever sexuality was included in curricular disciplines, it was usually associated with diseases following the traditional medical model instead of a more holistic approach. ${ }^{5}$

We note that these findings concerning the teaching of sexuality in nursing refer to the 1970s and 1980s; however, the difficulties identified at the time still persist in the current context. Only in 2000 is it possible to find a book such as "Sexual Health - Foundation for Practice" ${ }^{6}{ }^{6}$ in which the authors, two nurses, acknowledge that knowledge concerning human sexuality is a key element in nursing care and healthcare delivery.

The situation described in the 1970s and 1980s is similar to that observed in the context of the $21^{\text {st }}$ century in Brazil. Sexuality is currently seldom or almost never included in the curricula of nursing and medical schools. The emphasis of basic courses in nursing and medical programs, where sexuality could still receive focus, is on the male and female reproductive system, that is, on the reproductive process. There is no systematic guidance in the education of nurses on how to address sexual issues with patients. The discussion concerning the subject during the educational process seems to be isolated and occasional in undergraduate programs, where the theme is discussed due to individual or group initiatives. The university, however, has increasingly emphasized the importance of patients being acknowledged as individuals and cared for in a holistic manner. It is, therefore, important to plan nursing care so that it is unique and includes counseling in the sphere of sexuality ${ }^{7}$ as well, which means this subject should be mandatory in the education of nurses.

We note that sexuality and its correlation with nursing care is addressed in 36 hours of class in the course Interdisciplinary Studies III - Body, Gender and Sexuality in the Undergraduate Nursing Program at the Federal University of Santa Catarina, RG, Brazil, which undoubtedly is an advancement, and the program is a pioneer in Brazilian nursing education.

The existence of nurses with a specific background in sexuality at the graduate level is very 
rare in Brazil, as are such programs offered in the nursing field. The few professors working with this subject do it due to a personal interest.

This deficit of knowledge of human sexuality among health professionals results from how professional guidance centers on the biological aspects of sexuality, which has a cycling effect and reinforces the biological view of the subject. A lack of formal education concerning sexuality leads health professionals to deny help instead of working as facilitators. Often, due to prejudice, lack of knowledge, and the need to impose one's values, these professionals end up acting as destructive agents (iatrogenic). ${ }^{9}$

This scenario shows that professionals are still unprepared to discuss this topic with patients. Feeling insecure to provide such care, they deprive patients of appropriate care, often acting in an iatrogenic manner. "Iatrogenic, sexologic care includes contempt for and reinforcement of female sexual difficulties; the supply of unscientific information; suggesting that the patient separate from a spouse or seek an extramarital relationship; use of placebo; use of androgen agents when the patient does not meet the proper criteria; suggestion of a colpoperineoplasty to improve sexual performance; and having a personal relationship with the patient".$^{10: 70}$

We observe in our experience of supervising students providing nursing consultations to women in the primary healthcare service, during the preventive examination of breasts or a pap smear, or during prenatal care, or even family planning, that patients usually have complaints concerning their sexuality, present a lack of knowledge concerning human sexual response, anatomy, and female physiology and also have questions related to sexuality and gender, among others. We realized, given these complaints, the extent to which women's care practice is permeated by issues related to sexuality, which led to the need to deepen knowledge in the field.

To fill in this gap in the area of the relationship between sexuality and women's healthcare, a faculty member of the Undergraduate Program at the UFSC defended a master's thesis called "Female orgasm - from expression to the beginning of understanding", which sought to understand the female orgasm from the perspective of authors (researchers) and the women they studied ${ }^{11}$ As a consequence of this study, new research has been developed giving origin to a university extension project that was initiated in 1992, which provides care to women, and often their respective partners, in nursing consultations that focus on issues concerning experiences involving sexuality.

In 2007, this same professor concluded the Interdisciplinary Doctoral program in Human Sciences, with a major in Gender Studies, and defended a dissertation entitled "Female Sexuality and Sexual Pleasure: a Gender Approach", analyzing the reports of women's sexual practices obtained through 357 nursing consultations on sexuality that she provided. ${ }^{12}$ The academic background of this professor on women's sexuality studies enabled her to accumulate knowledge that led to the conclusion that women face difficulties experiencing a pleasurable sexual life as they experience contradictions that exist between information they receive, comparisons they hear, myths, representations they assume to be true, reproduction of concepts and values, and anguish that sexual practice may result when their sexual needs are not met.

Understanding that a satisfying sexual life is one of the pillars of health, thus, one of the objects of work for nurses, and aware there is a limited bibliography grounding care practice in the field, a template for nursing consultations concerning sexuality was developed at the primary healthcare level. We present this consultation in order to provide tools for nurses that they will heed complaints about sexuality at the primary healthcare level.

\section{NURSING CONSULTATION ON SEXU- ALITY}

It is important to clarify that the sexuality consultation we describe here was conceived and based on professional experience and knowledge concerning sexuality using normal instruments of nursing consultations, such as a nursing history, survey of problems (nursing diagnosis) and care planning (conduct). It is rather more dynamic than static, that is, it may have items added and/or removed, according to the particular need presented. The theoretical framework to be used can be freely chosen by professionals.

The first consultation takes on average two hours. Once the patient's needs are clarified, 
the patient is ensured that the consultation and information to be provided is absolutely confidential. A verbal contract is established through which the patient is instructed about the need for the nurse to "invade her privacy" and of the importance of providing details of aspects about which the patient is asked so that help will be possible. This procedure is followed by anamnesis addressing the woman's life from birth up to the time of consultation.

In addition to the date of consultation, the patient's history should contain the following: age, origin (urban or rural area), education, marital status, religion, age at the time of first sexual intercourse, motive of consultation, household composition, how they were raised (whether it included fondling, touching, sight of naked body), childhood games and play related to sexuality, perception of oneself as a sexual being, religion and sexuality, masturbation before and after having initiated sexual life, when sexual activity with penetration started, subsequent sexual life, current sexual life (communication of needs, masturbation, knowledge of one's body, sexual initiative, foreplay, orgasm, myths and taboos), description of current sexual intercourse, perception of her own sexuality, and perception of what orgasm and sexual life are in marital life. Based on these aspects, a diagnosis of what her problem is from her perspective is first established together with her and, thereafter, a nursing diagnosis is established. The emphasis is on health education on sexuality, sex education, based on the following: knowledge of the female and male anatomy, physiology of the human sexual response, review of the components of sexual scripts ${ }^{13}$ and confrontation of myths, taboos, and representations concerning women's sexuality that interfere in their experience, and specific sexual techniques, without directly initially focusing on the component of sexual life that led to the consultation (what sexologists call the dysfunctional component).

Return visits should be as many as necessary up to the point the patient verbalizes improvements in her sexual life or shows no interest in continuing to attend the consultations. The interval between one consultation and another should be less than a week because this is the time required to internalize behavior (care) that is to be reviewed. The average time of consultation varies. Some patients do not require more than a single consultation while others may require one year of follow-up with weekly consultations. In some cases, the partner may have to attend either joint or individual consultations.

\section{NURSING CONSULTATION ON SEXU- ALITY AND SEXOLOGY: SIMILARITIES AND DIVERGENCES}

The characteristics of sexual therapy include intensive and continuous treatment for two weeks and dysfunction linked to relational difficulties. The treatment presents two distinct phases: 1) data collection (four days) with sensorial education and 2) ten days in which orgasmic ability should be fully reestablished. Patients are not allowed to inform the partner of the content of individual interviews, and premature and non-gradual attempting to have an orgasm is proscribed. After the treatment is ended, patients are submitted to a surveillance of five years to evaluate relapses and encourage new treatment for patients who fail. . $^{14-15}$

There are points of convergence and divergence between nursing consultations in sexuality and sexology, which lead us to state that nurses do not act as sexologists despite working in the area of interface with this field. What are the areas of convergence and divergence between sexology and the nursing consultation in sexuality?

The main convergence between these two practices involves the agreement that sexual therapy departs from the principle that people with complaints have assimilated inappropriate scripts in regard to sexuality, which then may lead to sexual disorders. Hence, the procedure used to help solve sexual disorders can be seen as a manipulation of sexual scripts. ${ }^{14}$ Professionals working with sexual therapy, sexologists, psychologists or nurses, evaluate, together with each individual or couple, the content and functioning of their scripts, establishing a project of behavioral change that involves learning new interpersonal and intrapsychic scripts.

Divergences between nursing consultations and sexology are linked to the issue of diagnosis. A problem is only diagnosed in a nursing consultation addressing sexuality when it is perceived as a problem by the patient. In other words, what is not a problem for the patient is not a problem for the nurse. There is no intensified treatment 
with visits scheduled consecutively - the client defines the duration of the treatment; there is no monitoring after treatment or requirement of a return visit if the patient no longer wants to attend consultations; seeking orgasms is not proscribed, nor is communication between the couple about the interview prohibited; consultation is not necessarily provided to the couple; the focus is not the dysfunction but what is reported as being a problem by the patient. Also, in contrast to sexology, the focus in a nursing consultation on sexuality is not a "normal standard" to be followed or a pathology to be avoided or treated. There is no standardization strategy to the extent the patient/woman has her individuality respected and the consultation includes a process of deconstruction of taboos and paradigms related to gender.

We base this last statement on the studies of the physician and philosopher Georges Canguilhem. He defended a reformulation of medical clinical practice, that is, diagnosis and treatment should be based, above all, on the observation of the patient and not on modern techniques of examination. The perspective of the patient should be privileged because it is antecedent to scientific knowledge. ${ }^{16}$ According to this line of reasoning, both health and disease involve the consideration of sociopolitical aspects because human organic standards vary according to the social context, through the mediation of psychosomatic relationships. As the human species invented genders of life, they also invented physiological ways of being. ${ }^{16-17}$

As previously discussed, there are convergences and divergences between a nursing consultation concerning sexuality and sexology, thus, despite the fact nurses act in the interface with the latter, they do not do it with the quality of sexologists. They do not work at the level of therapy (in the traditional sense) but at the therapeutic level.

\section{NURSING AT THE PRIMARY HEALTH- CARE LEVEL AND WOMEN'S SEXUALITY}

Nurses and gynecologists who do not know what to do, or worse, are misinformed about what to do, when faced with a question concerning sexual matters are not rare. In general when these professionals graduate, they know a lot about diseases and treatments but very little about human sexuality. To work with human sexuality one must be well resolved concerning his/her own sexuality, know about human sexual response, and acquire a profound ethical respect in relation to another's sexuality. ${ }^{9}$

There are some characteristics that are necessary for professionals to work with sexuality issues, among which the following stand out: empathy - the ability to enter into the patient's frame of reference and communicate such understanding; congruence - the ability to be authentic in the interaction with the patient; unconditional acknowledgment - profound respect for another's sexuality; motivation - the ability to enable a predisposition to change; confrontation - the ability to work with the patient's strengths and make her confront her own paradigms; and concreteness - the ability to synthesize the discourse to the patient. ${ }^{5}$ The ability not to interfere and not to judge another should be added to these abilities, noting that each individual has the right to define his/her own sexual identity and nature of their full sexual realization.

It is, therefore, necessary for nurses to view the human being as an indivisible and individualized whole, with a history of life, inserted in a given context, based on a set of beliefs and values of a given culture. Only with this in mind nurses can be active participants in the health education process, walking alongside patients in a partnership on the path of self knowledge toward her "standard" (with the awareness that individual standards also vary according with the evolutional process and life experiences), instead of an external, often stereotyped standard, dictated by the media and/or literature, which makes one feel as she does not meet standards considered to be "normal".

As health professionals, the roles of nurses include that of "health educators". This is the focus that nursing consultations on sexuality at the primary healthcare level should have. At this level of care delivery, care practice should be integral, resolute, continuous and of good quality to meet the needs of the population. Health education in the context of sexuality means to clarify the anatomy of the female reproductive system, the (female and male) human sexual response, self-erotization, confrontation of sexual scripts, among others, demystifying beliefs and taboos that interfere with one's sexuality, helping patients to acquire self knowledge 
and practice self-care so that they recover their sexual potential, and consequently, their health potential.

It is common during nursing consultations addressing family planning, prenatal care, or during the preventive examination of breasts and pap smear, for complaints of a sexual nature to emerge. It is important to note that it is impractical to work with such sexual complaints during these consultations, since proper investigation requires a lengthy anamnesis and the availability of time from both the professional and the patient; a nursing consultation takes one hour and half to two hours on average. Therefore, frequently the best procedure is to provide the client some prior explanation and schedule a new consultation specifically to treat sexual complaints with the availability of time that is required.

The most frequent complaints refer to "frigidity" (lack of sexual desire or hypoactive sexual desire), pain during penetration (dyspareunia), lack of orgasm (anorgasmy), and rhythm of sexual activity and/or sexual desire dissonant with that of the partner (sexual inadequacy). All these dysfunctions can be classified as primary, that is, they were always there; secondary, when the dysfunction started to occur after a certain period/event; and situational, when they occur only under certain conditions. It is extremely important that any and all sexual complaints be investigated because it will determine the procedure to be implemented.

Lack of sexual desire or hypoactive sexual desire may be related to: a) hormonal factors, such as "low levels of dopamine and/or high levels of serotonin, hypo or hyperthyroidism, hyperprolactinemia, low level of testosterone" ${ }^{\prime 10: 67} \mathrm{~b}$ ) use of medication such as "antidopaminergic, alpha methyldopa, antiandrogen agents, serotonergic, tranquilizers" ${ }^{\prime 10: 67}$ and physicbiological factors such as inappropriate sexual education, sexual repression, taboos, beliefs, destructive experiences, sexual routinization, sexual inadequacy, dyspareunia, anorgasmy or even intrinsic motives that lead women not to allow themselves to receive pleasure and/ or give pleasure to their partners. It is important to investigate it with a good anamnesis to found out potential causes.

Dyspareunia is one of the most frequent causes. When faced with such a complaint one has to investigate whether it occurs at the beginning of penetration or during deep penetration. If the last is the case, verify whether it occurs always or occasionally, depending on the position adopted during sexual intercourse. If pain occurs at the beginning of penetration, it may be related to a lack of lubrication due to deficient estrogen, which is "common during menopause, postpartum, or after a prolonged use of anavolutory with low doses of estrogen and/or high doses of progesterone", ${ }^{10: 68}$ or lack of preparation (foreplay that takes into account the time women take to become aroused, fondling suitable for the woman in question) that leads to excitement. Dyspareunia may also be related to vulvitis or colpitis, which makes the vulva sensitive and sore to touch. In these cases, nurses can recommend the use of water-based vaginal lubricant for all women. The use of oil-based vaginal lubricant is counter-indicated in any situation because it may damage condoms (male preservatives) and/or alter the vaginal $\mathrm{pH}$.

In the event of regular dyspareunia with deep penetration, there is likelihood of colpitis, cervicitis, cervical cancer or other gynecological pathology, which will be either confirmed or ruled out at the end of the anamnesis or gynecological exam. If any of these pathologies are confirmed, the woman should be refereed to a gynecologist. When the woman reports situational dyspareunia that depends on the position adopted in coitus, it is probably caused by uterine static (anatomical position of the uterus and cervix). The woman should therefore be instructed to avoid positions that cause pain or acknowledge that pain is not a pathognomonic sign. It is worth noting that this type of dyspareunia, in addition to being caused by uterine static, may also be associated with pathologies such as those previously mentioned so that its investigation should not be discarded.

It is important to keep in mind the psychogenic causes of dyspareunia, among which we can highlight "phobic conditions (fear of pregnancy, sexually transmissible diseases, cancer, pain, etc.), dyadic inadequacy (pain becomes an unconscious way to "escape" from the relationship), identity conflicts and sexual role, rejection of the male figure and self-punishment" ${ }^{10: 68}$

Anorgasmy, sometimes erroneously called frigidity, consists of the woman's inability to 
obtain an orgasm, even if she has desire and becomes aroused. It is a frequent complaint among women regardless of age, education, marital status, socioeconomic or cultural condition. When facing this complaint, nurses should first ask the woman what she considers an orgasm to be and what body reactions it causes or should cause from her perspective. Physical and psychological reactions the woman has when aroused and during sexual intercourse should also be investigated. This investigation is very important since it is not rare that a woman's conception of orgasm is that presented by the media, or what she has learned from literature, or even what she believes to be standard based on other women's reports. Some women have orgasms and do not realize it because these do not follow the pattern they have built in their imagination.

If anorgasmy is in fact verified, patients should be given clarification about the anatomy of the reproductive system and physiology of human sexual response (using audiovisual resources) teaching her to know and recognize her own body, as well as her reactions through self-erotization. It is important to remember that in the Brazilian culture, the self-stimulation of the genitals by a woman is seen as a source of guilt and not of satisfaction. This guilt, in great part, results from condemnation of pleasure without reproductive purpose.

The use of some medications such as "ameltildopa, clonidine, fluoxetine, diazepam, alprazolam, clomipramine, imipramine, etc. may be associated with orgasmic inhibition". 10:69 In these cases, the patient should be referred to a gynecologist to change medication or to adjust dosage. "Stress urinary incontinence may determine secondary anorgasmy due to the woman's deep concern that urinary loss associated with the orgasm may occur" ${ }^{\prime 10: 69}$ It is also important to clarify and demystify differences between clitoral and vaginal orgasm, that penetration is not the only way to reach an orgasm, and stimulating the clitoris is important and part of the sexual game, and finally that masturbation has a therapeutic role in anorgasmy. ${ }^{10}$

Knowing one's own body and experiencing pleasure is very important for sexual performance because this learning leads to the discovery of more sensitive erogenous zones, of kinds of touch that arouse better, of better ways to incite desire. It is necessary to explain self-erotization and masturbation techniques to women and include clitoral stimulation because many women expect to have a vaginal orgasm when their response may effectively be clitoral. The bidet jet or the shower handset may help to stimulate the clitoris and enable many women to experience their first orgasm. It is necessary that women know how to obtain pleasure by themselves so they can obtain pleasure when sexually interacting with another. It is equally important to enable them to obtain their first orgasm, because once they reach it they will know they are not "frigid", that in reality they were not properly or correctly stimulated. It should be noted that obtaining an orgasm is not an obligation nor should it be demanded from the partner. Non-obligation frequently acts as a dysfunctional disarmer so that orgasm may occur in an unexpected and spontaneous way.

Women also need to be encouraged to talk about their desires, fantasies or sexual difficulties without being shy or ashamed, because this is the only way partners will be able to understand their partners and their sexual preferences. The path for pleasure is honest, free of simulation and fear.

When the woman's complaint refers to sexual inadequacy, it is necessary to first dismiss all other potential causes of sexual dysfunction. Once the possibility of dysfunction is discarded, one has to consider sexual inadequacy caused by a lack of knowledge on the part of the partner concerning human anatomy and erogenous areas, especially the female areas, and the difference between female and male sexual response, in terms of the mechanism that triggers desire and time for a woman to become aroused. It is often necessary to explain to the woman/couple about the female sexual response and anatomy, using audiovisual resources such as drawings and graphics, to show the differences between men and women, demystifying beliefs and taboos that interfere with the exercise of sexuality, helping patients in their quest for self-knowledge. It is important to realize that most "sexual dysfunctions" are in reality, sexual inadequacy, in which there is poor timing between the partners involved, or respect for the woman's physiological time, preferences or culture.

Therefore, consultations concerning sexuality involve multidimensional aspects. The establishment of bonds between nurses and patients is 
required to approach these aspects and facilitate discussion because through health education, nurses open up a space where aspects relevant to sexuality in the different stages of a patient's life cycle, which involve aspects other than the biological, such as social, cultural and psychological aspects. ${ }^{18}$ It should be emphasized that there is no pattern of normality to be followed, but rather a unique woman with her culture and history of life who will express her sexuality in her unique and particular manner.

\section{FINAL CONSIDERATIONS}

The importance human sexuality has acquired in modern times increases the demand to heed complaints related to it daily, especially for professionals working with women's health at the primary healthcare level.

Being qualified to heed issues inherent to sexuality also includes constantly rethinking the practice of such care and in this context, regular updating is required for nurses to approach sexuality issues, without reducing them strictly to biological aspects. Also required is comprehension of one's perceptions about body, pleasure/displeasure, affective values, and being responsible for oneself, among other aspects and emerging values concerning sexuality in modern times. This nursing practice meets the recommendations of National Nursing Curricular Guidelines ${ }^{19}$, as elements that guide content and competencies of nurses defining the profile of nurses as "those able to identify and intervene in health-disease problems/situations, identifying the biopsychosocial dimensions of their determinants, able to act with a sense of social responsibility and commitment to citizenship and as a promoter of integral health delivered to human beings". ${ }^{19: 37}$

In this context, deepening the study of human sexuality, especially female sexuality, is one of the requirements in the education and practice of nurses so that they can provide primary care committed to the population's health needs, especially, women's health needs, in agreement with the recommendations of the National Nursing Curricular Guidelines.

\section{REFERENCES}

1. Foucault M. Microfísica do poder. Rio de Janeiro (RJ): Graal, 2008.
2. Pelá NTR, Melo AS, Santana WMS, Nhamba AL. A sexualidade humana no contexto da assistência de enfermagem. Rev Bras Sex Hum. 1995 Jan; 6(1):99113.

3. Magnety J. A plea for sex education in nursing curriculauns. Am J Nurs. 1975 Aug; 7(1):197-204.

4. Mims F. Sexual health education and and counseling. Nurs Clin North Am. 1975 Sep; 10(3):519-28.

5. Whipple B, Gick R. A holistic view of sexuality education for the health professional. Clinic Nurs. 1980 Jan; 1(4):90-1.

6. Wilson H, MacAndrew S. Sexual health: foundations for practice. Edinburgh: New York (US): Baillière Tindall, 2000.

7. Santos LV, Ribeiro AO, Campos MPA. Habilidade do acadêmico de enfermagem para lidar com a sexualidade do cliente. Rev Min Enferm [online]. 2007 Jan-Mar [acesso 2011 Abr 08]; 11(1):325. Disponível em: http://www.revenf.bvs. br/scielo.php?script $=$ sci_arttext\&pid=S141527622007000100005\&lng=pt

8. Ribeiro MO. A sexualidade segundo Michel Foucault: uma contribuição para enfermagem. Rev Esc Enferm USP [online]. $1999 \mathrm{Dez}$ [acesso 2011 Abr 10]; 33(4):358-63. Disponível em: http:/ / www.scielo. br/pdf/reeusp/v33n4/v33n4a06.pdf

9. Montgomery M, Lopes GP, Noronha D. Tocoginecologia psicossomática. São Paulo (SP): Almed; 1993.

10. Trapani A. Disfunção sexual. In: Grando LB, organizador. Ginecologia e obstetrícia: manual de terapêutica - Associação Catarinense de Medicina. Blumenau (SC): Nova Letra; 2006. p. 66-71.

11. Garcia ORZ. Orgasmo feminino: da expressão ao início da compreensão [dissertação]. Florianópolis (SC): Universidade Federal de Santa Catarina, Programa de Pós-Graduação em Enfermagem; 1991.

12. Garcia ORZ. Sexualidades femininas e prazer sexual: uma abordagem de gênero. Rev Terapia Sexual. 2009 Jan-Jun; XI(2):93-128.

13. Gagnon JH. Os roteiros e a coordenação da conduta sexual. In: Gagnon JH. Uma interpretação do desejo: ensaios sobre o estudado da sexualidade. Rio de Janeiro (RJ): Garamond, 2006. p. 111-49

14. Béjin A. Crepúsculo dos psicanalistas e manhã dos sexólogos. In: Ariés P, Béjin A, organizador. Sexualidades ocidentais: contribuições para a história e para a sociologia da sexualidade. São Paulo (SP): Brasiliense; 1987. p. 211-35.

15. Béjin A. O poder dos sexólogos e a democracia sexual. In: Ariés P, Béjin A, organizador. Sexualidades ocidentais: contribuições para a história e para a sociologia da sexualidade. São Paulo (SP): Brasiliense; 1987. p. 236-54. 
16. Canguilhem G. O normal e o patológico. Rio de Janeiro (RJ): Forense Universitária; 2000.

17. Bozon M. Sociologia da sexualidade. Rio de Janeiro (RJ): Editora FGV; 2004.

18. Trindade WR, Ferreira MA. Sexualidade feminina: questões do cotidiano das mulheres. Texto Contexto Enferm [online]. 2008 Set [acesso 2012 Fev 25]; 17(3):417-26. Disponível em: http://www.scielo.
br/scielo.php?script=sci_arttext\&pid=S010407072008000300002\&lng=pt

19. Ministério da Educação (BR). Conselho Nacional de Educação. Câmara de Educação Superior. Resolução CNE/ CES n. 3, de 7 novembro de 2001. Institui as Diretrizes Curriculares Nacionais do Curso de Graduação em Enfermagem. Diário Oficial da República Federativa do Brasil. Brasília (DF), 9 nov. 2001. Seção 1, p. 37. 